\title{
Teaching microbiological food safety through case studies
}

\author{
Florence Dubois-Brissonnet ${ }^{\mathrm{a}^{*}, \mathrm{~b}}$, Laurent Guillier ${ }^{\mathrm{c}}$, And Murielle Naïtalia ${ }^{\mathrm{a}}$ \\ a AgroParisTech, Food Science \& Technology dept, F-91300 Massy, France \\ ${ }^{\mathrm{b}}$ INRA, UMR Micalis, F-91300 Massy, France \\ ${ }^{c}$ Anses, French agency for food, environmental and occupational health and safety, F-94700, Maisons-Alfort \\ ${ }^{*}$ Corresponding author \\ florence.dubois-brissonnet@agroparistech.fr \\ TEL: +33-1-69736472
}

Received: 29 June 2014; Published online: 18 October 2015

Invited paper from the $3^{\text {rd }}$ International ISEKI_Food Conference - ISEKI_Food 2014 - Bridging Training and Research for Industry and the Wider Community - Food Science and Technology Excellence for a Sustainable

Bioeconomy

\begin{abstract}
Higher education students usually ask for more training based on case studies. This was addressed by designing a specific food safety module (24 hours) in which students were shown how to predict microbiological risks in food products i.e. they were asked to determine product shelf-life according to product formulation, preservation methods and consumption habits using predictive microbiology tools. Working groups of four students first identified the main microbiological hazards associated with a specific product. To perform this task, they were given several documents including guides for good hygiene practices, reviews on microbiological hazards in the food sector, flow sheets, etc... After three-hours of work, the working groups prepared and gave an oral presentation in front of their classmates and professors. This raised comments and discussion that allowed students to adjust their conclusions before beginning the next step of their work. This second step consisted in the evaluation of the safety risk associated with the two major microbiological hazards of the product studied, using predictive microbiology. Students then attended a general lecture on the different tools of predictive microbiology and tutorials (6 hours) that made them familiar with the modelling of bacterial growth or inactivation. They applied these tools (9 hours) to predict the shelf-life of the studied product according to various scenarios of preservation (refrigeration, water activity, concentration of salt or acid, modified atmosphere, etc...) and/or consumption procedures (cooking). The module was concluded by oral presentations of each working group and included student evaluation (3 hours).
\end{abstract}

Keywords: Case studies; Food safety; Predictive microbiology

\section{Introduction: Objectives of the training}

These days, students prefer having less theoretical lectures and more case studies that are relevant to their future professional issues. In this context, an original food safety module (24 hours) based on case studies was designed. Students were given one food product and were asked to determine which mode of preservation would be best and how long the associated shelflife of this product should be. These questions were professionally relevant as the determination of shelf-life of food products is the responsibility of manufacturers who increasingly employ predictive microbiology tools. The proposed approach was therefore relevant for the future career of students. While developing knowledge in 
Food safety case studies $\mid 135$

microbiology, the overall objective of this module was to provide students with training that could help them develop their ability to solve problems and to take decisions.

\section{Organization of the training}

This food safety module is an optional module intended for engineering students (Year 4, second year in AgroParisTech) or master students (first year) interested in microbiological food safety. The prerequisite for attending this module was to have general knowledge in both microbiological food quality and foodborne infections.

The module included lectures, tutorials and a team working case study. The latter was introduced through description of an example of a recent outbreak that led to a shelf-life reduction of the implicated product (French rillettes). Newspaper articles describing the crisis were first analysed by students and a discussion, initiated by professors, led the students to identify the problem and its origin, to propose solutions and to compare them to that selected by professionals. The students were then split into groups of 4 people for the case study. Working as a team was part of the training. This taught students how to manage group dynamics, improve communication skills, and develop their ability to raise questions. Each group identified the two main microbiological hazards associated with a specific food product, evaluated the microbial safety risk associated with these hazards and determined the relevant shelf-life. A different food product was taken on by each group. The students could choose the food product they want to study among a list of products which had been previously selected by professors for their ability to raise open-ended problems: more than one solution could be proposed for their preservation. Cooked ham, minced raw meat, fresh fish, poultry fillets, smoked salmon, packaged freshcut salad, zucchini puree and pasteurized milk were some of the proposed products that could be studied. The diversity of the products allowed an exchange of information during oral presentations and expanded the students' body of knowledge.

Professors supervised the module together with a consultant from ANSES, the "French agency for food, environmental and occupational health and safety". This allowed aligning the module to both the food manufacturers' concerns and to the whole learning objectives of the training.

\section{First issue: how can one identify and classify microbiological hazards in a food product?}

This first part of the team project was designed to identify microbiological hazards in food products. Students had in previous lectures learned about the main foodborne pathogens, their growth pattern, survival rate and resistance characteristics, effects on human health, the routes of contamination, the potential incriminated foods, the epidemiology and the analytical methods. The knowledge acquired during lectures was applied and strengthened the students' learning process. Professors gave each group a file with a selection of scientific literature, books, hygiene guidelines and regulations that could help analyse the product process and potential microbiological hazards (spoilage microorganisms, foodborne pathogens). Students did not rely exclusively on the provided information and were encouraged to search for supplementary data in the university library, where librarians together with professors helped them find appropriate sources of information.

While categorizing microbiological hazards, students also had to identify parameters that could affect microbial growth (temperature, atmosphere in packaging, salt concentration) in their food product and to select the most appropriate parameters for further studies. Students had six hours to understand and evaluate information, articulate their thoughts and prepare a quick oral presentation that included data projection using slides. They presented their results of hazard identification and justified their prioritization. For example, Bacillus cereus (as spore forming-bacteria) appeared as a relevant hazard in pasteurized products such as zucchini puree or pasteurized milk. Moreover, students were asked to propose various solutions to control the main hazards and to state which scenarios of preservation should be chosen for the second part of

\begin{tabular}{l|l|l|l} 
IJFS | October 2015 | Volume 4 & pages 134-140
\end{tabular} 
the module. A discussion could take place with other students to exchange views on the selected modes of preservation. A first assessment of the group was done from this oral presentation.

\section{Second issue: which scenarios of preservation can one choose and what is the corresponding shelf-life?}

This part of the project intended to develop students' ability to determine a product shelf-life depending on various scenarios of preservation. The shelf-life of a product can be selected by different means that are listed in the annexe II of the European regulation (EC) n²073/2005 (ItieHafez \& Danan, 2014). In this training, the students employed predictive microbiology to predict the growth or the inactivation of microorganisms in relation to their environment using different mathematical models, databases and software (Delhalle, Daube, Adolphe, Crevecoeur, \& Clinquart, 2012; Tenenhaus-Aziza \& Ellouze, 2015). So, students first attended a general lecture on predictive microbiology together with additional tutorials that helped students to better understand the modelling and its limits and to manipulate several tools of predictive microbiology (software, web-based resources). Afterwards, students applied these recently acquired skills to determine shelf-life of their own products according to various scenarios they imagined. The repetition of similar exercises, first in tutorials and then with more freedom in the framework of a project, allowed students to reformulate the questions, to appropriate and integrate the approach and its implementation.

\subsection{Tutorials to learn tools in predictive microbiology}

Six hours were dedicated to teaching different models that are useful in food microbiology. First, microbial growth needs two types of modelling:

- Primary growth models give the growth of the microbial population as a function of time $(N=\mathrm{f}(t))$ in constant environmental conditions. The adjustment of the models to experimental data allows determination of relevant parameters such as the duration of the lag phase (lag) and the maximal specific growth rate $\left(\mu_{\max }\right)$. The most common models were described and utilized, from the simplest exponential model to more complex ones such as Gompertz, logistic or Baranyi \& Roberts models (Zwietering, Jongenburger, Rombouts, \& Van't Riet, 1990; Baranyi \& Roberts, 1994; Rosso et al., 1996). In the tutorials, students compared results obtained from the adjustment of different models when applied on a same data set.

- Secondary growth models describe the evolution of $\mu_{\max }$ as a function of the environmental conditions such as temperature, $\mathrm{CO}_{2}$ concentration, etc $\left(\mu_{\max }=\mathrm{f}\left(T,\left[\mathrm{CO}_{2}\right]\right.\right.$, ...)). Polynomial, square root or cardinal models (Ratkowsky, Olley, Mcmeekin, \& Ball, 1982; Rosso, Lobry, \& Flandrois, 1993; McClure et al., 1994; Ross \& Dalgaard, 2004) were described and applied in tutorials to evaluate the shelf-life of apple compote under pre-defined conditions of storage. Students compared the value obtained with different primary and secondary models to those given by the free web-based resources, Combase (www.combase.cc) and Pathogen Modelling Program (pmp.errc.ars.usda.gov/ PMPOnline.aspx). The divergence of the results obtained and the impact on the choice of the shelf-life was discussed in relation to the type of hazard and its level. Students were often concerned by the wide range of values obtained for the shelf-life depending on the model utilized. This led them to begin to exercise a critical approach to results.

Secondly, students were taught how to use models of bacterial inactivation, in order to predict the impact of cooking for example. As for growth models, there are two types of inactivation models:

- Primary inactivation models feature the evolution of a microbial population as a function of time under constant environmental conditions (for example, at $100^{\circ} \mathrm{C}$ ). 
Food safety case studies |137

Some models like log-linear model, biphasic or Weibull models (Geeraerd, Valdramidis, \& Van Impe, 2005) were described and students could test them upon a provided data set using GinaFit (Geeraerd et al., 2005), a freeware Add-in for Microsoft Excel software (cit.kuleuven.be/biotec/ginafit.php).

- Secondary inactivation models describe the impact of environmental conditions upon inactivation parameters. Some common models, like Bigelow or Mafart models (Couvert, Gaillard, Savy, Mafart, \& Leguerinel, 2005) were described. In tutorials, students could evaluate which parameter had the highest impact on the logarithmic destruction of a microbial population when several factors varied together. These models highlighted important microbial behaviour: for example, an increase of temperature appeared more efficient than an increase of time to eradicate a given level of microorganisms.

\subsection{Team work project: impact of environmental parameters on growth rate}

Back in their group and to their chosen food product, students took possession of the mathematical tools and using databases, mainly Combase (Baranyi \& Tamplin, 2004), or data from literature. Students extracted some experimental data of growth rate obtained in their food product (which is rare) or mainly in culture medium for the main microbiological hazards they had previously identified according to impacting environmental factors. They then applied a relevant secondary model for determining the bacterial growth rate according to this factor. For example, Figure 1 illustrates the growth rate modelling according to temperature for nonpsychrotrophic strains of Bacillus cereus in culture medium, as well as the cardinal temperatures. This was obtained using the Rosso's model (Rosso et al., 1993) and data from literature (Carlin et al., 2013). Additionally, students used the few growth rates obtained from challenge-test experiments carried out in the same food category as their studied product (for example $B$. cereus in zucchini puree) to calibrate their models and thus obtained more realistic predictions (Membre et al., 2005). Using other relevant models and depending on the impacting parameters for their product, students could determine the impact of different formulations such as concentrations of preservative such as salt (in connection with water activity), acids, nitrites, etc... or of various atmospheres of packaging on the growth rate values.

\subsection{Team work project: determination of the product shelf-life according to scenarios of preservation}

Legislation stipulates that the shelf-life (that is the manufacturer's responsibility) must also provide information regarding the expected storage conditions. The last student task thus consisted of definition and consideration of a variety of plausible scenarios of preservation i.e. several phases of storage at different temperatures or under different atmospheres (before and after opening the packages). To do so, students integrated supplementary data such as, in the case of refrigerated products, the time spent in commercial and domestic fridges, the mean fridge temperature and the variation of fridge temperature, etc... using survey data (James, Evans, \& James, 2008; Lagendijk, Assere, Derens, \& Carpentier, 2008).

For example, pasteurized milk, which is supposed to be contaminated with 1 Bacillus cereus spore per gram, can be stored 2 days at $4^{\circ} \mathrm{C}$ in the factory, 2 days at $7^{\circ} \mathrm{C}$ at the retail and a few days in the consumer's fridge. The limit of hazardousness $\left(10^{5}\right.$ bacteria/g) will be reached at different times according to the fridge temperature and shelf-life can thus be calculated under these conditions (Figure 2). In this particular case, shelflife can vary from 21 days at $7^{\circ} \mathrm{C}$ to only 6 days at $12^{\circ} \mathrm{C}$. This raised the students' awareness of the importance of controlling the fridge temperature.

Other factors were taken into account to determine the shelf-life $e . g$. packaging under $\mathrm{CO}_{2}$, decreased salt or nitrite concentrations for nutritional purposes. With the help of the devel-

\begin{tabular}{l|l|l|l} 
IJFS | October 2015 | Volume 4 & pages 134-140
\end{tabular} 


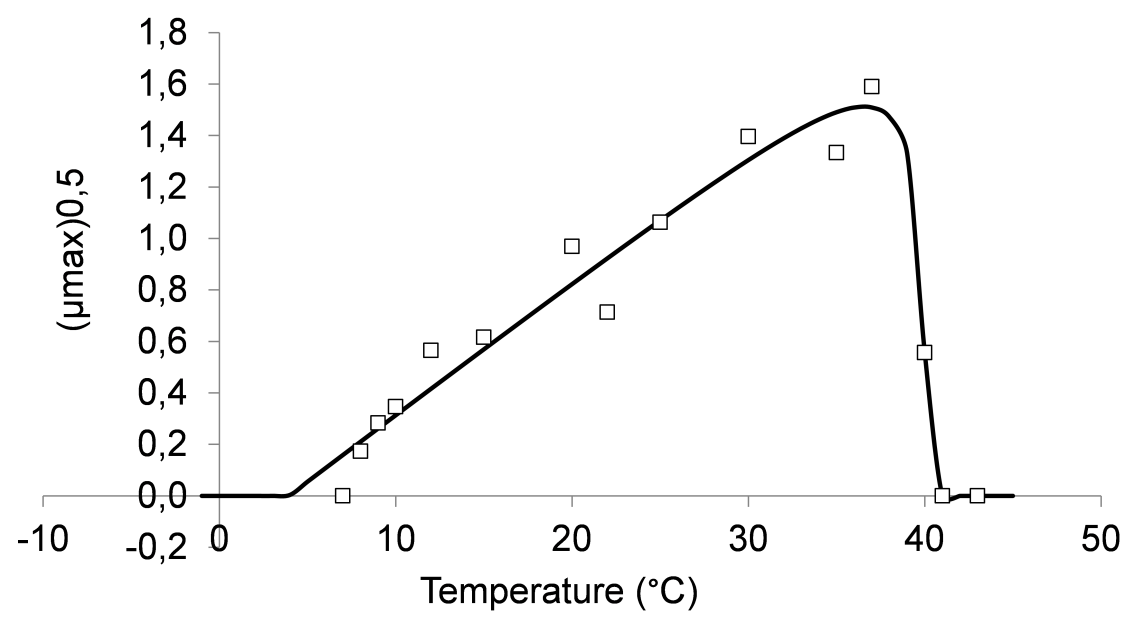

Figure 1: Growth rate of non-psychotropic strains of Bacillus cereus according to temperature. Experimental data were obtained from the literature (Carlin et al., 2013) and fitted using the Rosso's model (Rosso, Lobry, \& Flandrois, 1993)

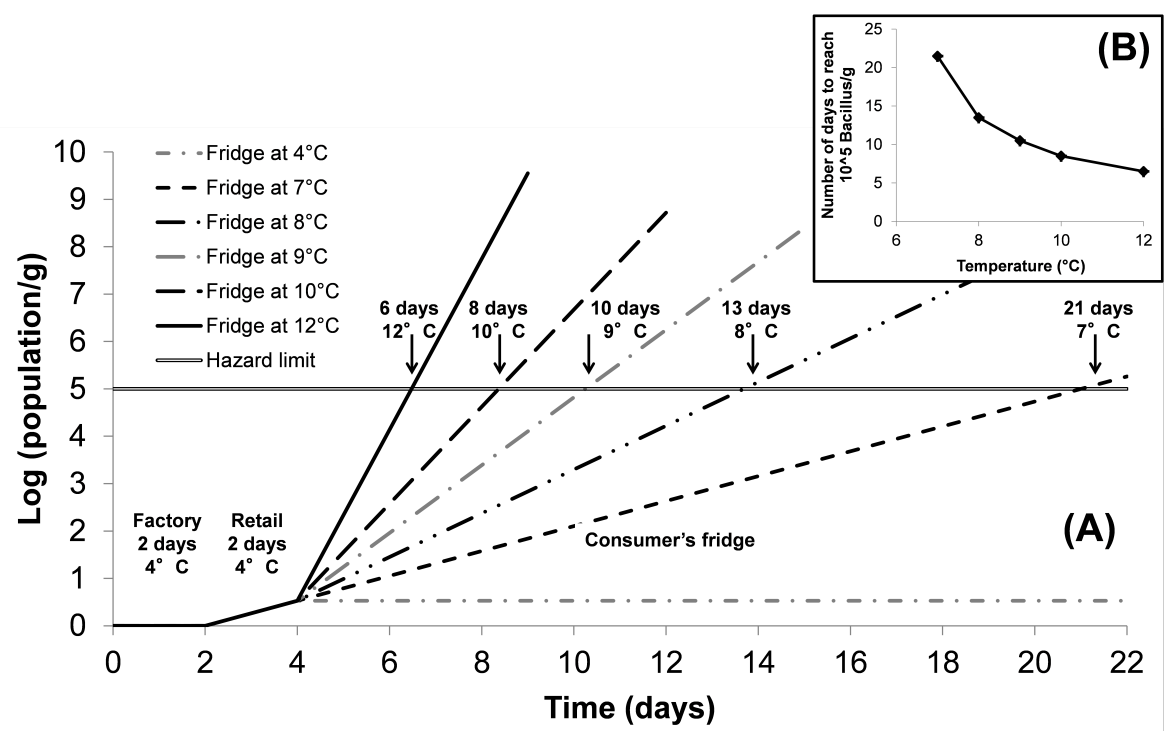

Figure 2: Modelling of growth of a psychotropic Bacillus cereus during the different phases of storage (A) and number of days to reach $10^{5}$ bacteria/g (B), according to the fridge temperature. The values of $\mu_{\max }$ at the different temperatures were obtained from a square root secondary predictive model and then used in the primary predictive model of exponential growth without lag phase 
oped models, students could quantitatively address some practical questions: what is the consequence of using modified-atmosphere packaging on shelf-life, which concentration of lactate should be added to the product to compensate for the reduction of salt, what is the best cooking time-temperature recommended to the consumer to minimise bacterial risks, what is the increase of shelf-life obtained thanks to the use of a biopreservation microflora?

Finally, students had to establish a rational shelflife based on the available information and on foreseen uncertainties. They had to justify their choice with safety concerns but also with performance and cost concerns. They were asked to establish a safety margin from these data and to take into account the consumer understanding of the label "use by date". They learned to review and organize information depending on their priorities and to develop skills that can be applied to solve various problems.

Students had 9 hours to work on the second issue of their case and this included creating the scenarios, choosing the most demonstrative ones, and preparing the final oral presentation. After presentation of the various scenarios and the respective associated shelf-life, discussion could take place between students and professors about the choice of the best way to preserve the product. The final assessment of the group was done from this oral presentation.

\section{Conclusions}

This module provided progressive guidance in order to make students familiar with predictive microbiology. It made students more aware of both their available knowledge and the additional information they needed to find to propose a solution for the product preservation. They became aware of how and in which proportion each environmental parameter could impact the product's shelf-life.

Along this module, students' skills such as problem-solving and decision-making were developed. It also promoted students' self-confidence in their ability to propose solutions. They acquired knowledge but also know-how and knowbe through an active, integrated and construc- tive process. Globally, this type of pedagogy developed students' interest in the subject matter, here predictive microbiology, and helped students to become self-directed learners. The increase in students' motivation could be assessed through the high demand for this course which was very well evaluated by the students.

\section{References}

Baranyi, J. \& Roberts, T. A. (1994). A dynamic approach to predicting bacterial-growth in food. International Journal of Food Microbiology, 23(3-4), 277-294. doi:10.1016/ 0168-1605(94)90157-0

Baranyi, J. \& Tamplin, M. L. (2004). Combase: a common database on microbial responses to food environments. Journal of Food Protection, 67(9), 1967-1971. 1st International Conference on Microbiological Risk Assessment - Foodborne Hazards, Adelphia, MD, JUL 24-26, 2002.

Carlin, F., Albagnac, C., Rida, A., Guinebretiere, M.-H., Couvert, O., \& Nguyenthe, C. (2013). Variation of cardinal growth parameters and growth limits according to phylogenetic affiliation in the bacillus cereus group. consequences for risk assessment. Food Microbiology, 33(1), 69-76. doi:10.1016/j.fm.2012.08.014

Couvert, O., Gaillard, S., Savy, N., Mafart, P., \& Leguerinel, I. (2005). Survival curves of heated bacterial spores: effect of environmenta factors on weibull parameters. International Journal of Food Microbiology, 101 (1), 73-81. doi:10.1016/j.ijfoodmicro . 2004.10.048

Delhalle, L., Daube, G., Adolphe, Y., Crevecoeur, S., \& Clinquart, A. (2012). A review of growth models in predictive microbiology to ensure food safety. Biotechnologie Agronomie Societe et Environnement, $16(3), 369-381$.

Geeraerd, A. H., Valdramidis, V., \& Van Impe, J. F. (2005). Ginafit, a freeware tool to assess non-log-linear microbial survivor curves. International Journal of Food Microbiology, 102(1), 95-105. doi:10.1016/j. ijfoodmicro.2004.11.038 
Itie-Hafez, S. \& Danan, C. (2014). Comment déterminer la durée de vie microbiologique des aliments? Industries Agricoles et Alimentaires, 05/06, 35-37.

James, S. J., Evans, J., \& James, C. (2008). A review of the performance of domestic refrigerators. Journal of Food Engineering, 87(1), 2-10. 17th International Congress of Chemical and Process Engineering (CHISA), Prague, CZECH REPUBLIC, AUG 27-31, 2006. doi:10.1016/ j.jfoodeng.2007.03.032

Lagendijk, E., Assere, A., Derens, E., \& Carpentier, B. (2008). Domestic refrigeration practices with emphasis on hygiene: analysis of a survey and consumer recommendations. Journal of Food Protection, 71(9), 18981904.

McClure, P. J., Blackburn, C. D., Cole, M. B., Curtis, P. S., Jones, J. E., Legan, J. D., ... Walker, S. N. J. (1994). Modeling the growth, survival and death of microorganisms in foods - the UK food micromodel approach. International Journal of Food Microbiology, 23(3-4), 265-275. doi:10.1016/ 0168-1605(94)90156-2

Membre, J. M., Leporq, B., Vialette, M., Mettler, E., Perrier, L., Thuault, D., \& Zwietering, M. (2005). Temperature effect on bacterial growth rate: quantitative microbiolog approach including cardinal values and variability estimates to perform growth simulations on/in food. International Journal of Food Microbiology, 100(13), 179-186. 4th International Conference on Predictive Modelling in Foods, Quimper, FRANCE, JUN 15-19, 2003. doi:10 . 1016/j.ijfoodmicro.2004.10.015

Ratkowsky, D. A., Olley, J., Mcmeekin, T. A., \& Ball, A. (1982). Relationship between temperature and growth-rate of bacterial cultures. Journal of Bacteriology, 149(1), 15.

Ross, T. \& Dalgaard, P. (2004). Modeling microbial responses in food. In R. McKellar \& X. Lu (Eds.), (Chap. Secondary models, pp. 63-150). CRC Press LLC.

Rosso, L., Bajard, S., Flandrois, J. P., Lahellec, C., Fournaud, J., \& Veit, P. (1996). Differential growth of listeria monocytogenes at 4 and 8 degrees c: consequences for the shelf life of chilled products. Journal of Food Protection, 59(9), 944-949.

Rosso, L., Lobry, J. R., \& Flandrois, J. P. (1993). An unexpected correlation between cardinal temperatures of microbial-growth highlighted by a new model. Journal of Theoretical Biology, 162(4), 447-463. doi:10.1006/ jtbi.1993.1099

Tenenhaus-Aziza, F. \& Ellouze, M. (2015). Software for predictive microbiology and risk assessment: a description and comparison of tools presented at the icpmf8 software fair. Food Microbiology, 45(B), 290-299. doi:10.1016/j.fm.2014.06.026

Zwietering, M. H., Jongenburger, I. 1., Rombouts, F. M., \& Van't Riet, K. (1990). Modeling of the bacterial growth curve. Applied and environmental microbiology, 56(6), 18751881. 